\title{
Penerapan Media E-Learning Berbasis Moodle Pada Jurusan Teknik Informatika Dan Sistem Informasi Universitas Trisakti
}

\author{
Gatot Budi Santoso ${ }^{\text {; Frisca Adiesthy Irdiani }}{ }^{2}$; Nita Chairunnisa ${ }^{3}$; Tondi Mulia Sinaga ${ }^{4}$ \\ 1, 2, 3,4Jurusan Teknik Informatika Universitas Trisakti \\ ${ }^{1}$ gbs@trisakti.ac.id
}

\begin{abstract}
This study aims to apply moodle e-learning to Trisakti University students majoring in informatics engineering and information systems, knowing the feasibility of e-learning produced as a source of student learning, and revealing the effectiveness of e-learning towards the achievement of student learning outcomes. This study shows that e-learning was developed with Moodle through three stages, namely: first planning, design, and development, both e-learning is feasible to use for students, and the third is the application of e-learning to Trisakti University students majoring in informatics engineering and systems information effectively improves student cognitive learning outcomes. This is evidenced by the survey conducted by the author
\end{abstract}

Keywords: e-learning moodle, trisakti university

\begin{abstract}
ABSTRAK
Penelitian ini bertujuan untuk menerapkan e-learning moodle pada mahasiswa Universitas Trisakti Jurusan Teknik Informatika dan Sistem Informasi, mengetahui kelayakan e-learning yang dihasilkan sebagai sumber belajar mahasiswa, dan mengungkap keefektifan e-learning terhadap pencapaian hasil belajar mahasiswa. Penelitian ini menunjukkan bahwa e-learning yang dikembangkan dengan Moodle melalui tiga tahapan, yaitu : pertama perencanaan, desain, dan pengembangan, kedua elearning tersebut layak digunakan pada mahasiswa, dan ketiga penerapan e-learning kepada mahasiswa Universitas Trisakti Jurusan Teknik Informatika dan Sistem Informasi efektif meningkatkan hasil belajar kognitif siswa. Hal ini terbukti dengan survey yang telah dilakukan penulis.
\end{abstract}

Kata kunci: e-learning moodle, universitas trisakti 


\section{PENDAHULUAN}

Perkembangan teknologi sangat memungkinkan pembelajaran dapat dilakukan dari jarak jauh secara online. Sistem pembelajaran saat ini tidak hanya dilakukan di sekolah atau di kampus tetapi dapat dilakukan di manapun dan kapanpun [4]. Sistem pembelajaran e-learning adalah cara baru dalam proses belajar mengajar. E-learning merupakan dasar dan konsekuensi logis dari perkembangan teknologi informasi dan komunikasi. Dengan e-learning, peserta ajar (learner atau mahasiswa) tidak perlu duduk dengan manis di ruang kelas untuk menyimak setiap ucapan dari seorang dosen secara langsung. E-learning juga dapat mempersingkat jadwal target waktu pembelajaran, dan tentu saja menghemat biaya yang harus dikeluarkan oleh sebuah program studi atau program pendidikan. Dengan e-learning dosen juga bisa menyampaikan materi pembelajaran melalui internet sehingga mahasiswa dapat mengakses materi tersebut kapan saja dan dari mana saja [1].

E-learning merupakan salah satu bentuk metode pembelajaran yang dipersepsikan bersifat student centered. Pemanfaatan e-learning diharapkan dapat memotivasi peningkatan kualitas pembelajaran dan materi ajar, kualitas aktivitas dan kemandirian mahasiswa, serta komunikasi antara dosen dengan mahasiswa maupun antar mahasiswa. Kini banyak portal e-learning yang dikembangkan dengan perangkat lunak Content Management System (CMS) dan juga Learning Management System (LMS), salah satunya adalah Moodle. Beberapa contoh aplikasi berbasis CMS yang lain adalah Dolibarr. Dolibarr (Open ERP) adalah aplikasi ERP modern dan lengkap yang didistribusikan secara open source, dimana didalamnya terdapat berbagai program aplikasi bisnis termasuk Sales, CRM, Human Resources, Warehouse Management, Finance dan Accounting. [2]

Moodle atau Modular Object-Oriented Dynamic Learning Environment merupakan perangkat lunak open source yang mendukung implementasi e-learning dengan paradigma terpadu dimana berbagai fitur penunjang pembelajaran dengan mudah dapat diakomodasi dalam suatu portal $e$ learning. Moodle berfokus pada memberi pendidik alat terbaik untuk mengelola dan mempromosikan pembelajaran dan memungkinkan dosen untuk mengatur, mengelola dan memberikan materi pelajaran. Dari sudut pandang didaktik, penggunaan alat multimedia untuk menciptakan aktivitas menarik membuat proses belajar lebih bersahabat bagi mahasiswa. Sebagai konsekuensinya, kegiatan ini meningkatkan minat mahasiswa dalam belajar. dosen dapat memberi mahasiswa sejumlah besar sumber daya yang biasanya tidak dapat mereka tunjukkan di kelas karena kendala waktu. Tugas pelajaran dalam Moodle dapat dikaitkan dengan sumber daya apapun yang diupload ke server seseorang atau yang tersedia di Internet. Eksplorasi mahasiswa terhadap sumber berbasis konten dapat dengan mudah dinilai dengan menggunakan alat evaluasi dan umpan balik berbasis Moodle. CMS e-learning berbasis

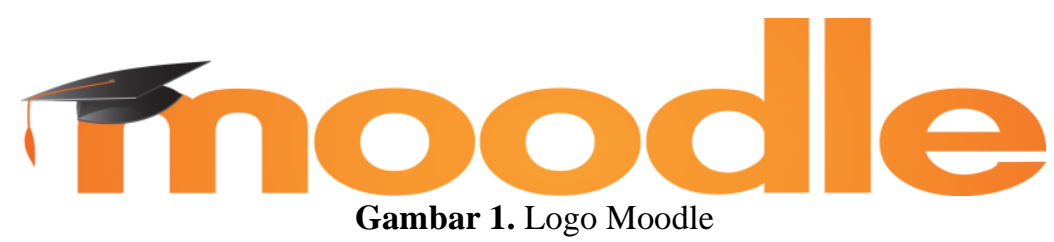

Moodle menggunakan logo seperti ditunjukan dalam Gambar 1

\section{METODE PENELITIAN}

Aplikasi e-learning ini menjelaskan tentang seputar materi perkuliahan yang di dapat pada jurusan Sistem Informasi pada umumnya. Tidak menutup kemungkinan materi perkuliahan akan berkembang menjadi lebih luas cakupannya. Website ini terdiri dari dua jenis halaman, yaitu halaman 
Front End dan Back End. Halaman Front End merupakan halaman yang dapat diakses oleh Student dan Guest atau dikenal dengan sebutan Public Site. Halaman Front End memiliki kategori, diantaranya halaman Course yang tersedia, Course yang diambil, Test, Schedule dan Room Chat. Namun, pada website kami, guest hanya bisa melihat mata kuliah yang terlihat pada halaman utama, jika guest ingin mengakses isi mata kuliah yang ada maka guest diwajibkan untuk membuat akun ataupun login terlebih dahulu. Lalu, halaman Back End merupakan halaman yang hanya bisa diakses oleh Administrator dan beberapa role lainnya, yaitu Course Creator dan Teacher. Administrator adalah orang yang bertugas mengelola website e-learning https://pakarseminar.id/moodle30

Administrator memiliki kuasa penuh untuk memposisikan dan mengelola sebagai role apapun, baik itu course creator, teacher bahkan student dan guest untuk mengecek tampilan dari masingmasing role. Course Creator bertugas untuk memasukkan matakuliah baru ke dalam website dan tipe perkuliahannya. Teacher adalah pemberi materi, tugas, test dan berinteraksi terhadap Student di setiap matakuliah.

\subsection{FITUR FITUR MOODLE}

Moodle merupakan produk yang aktif dan cepat perkambangannya [6]. Seiring perkembangannya, banyak fungsi-fungsi baru yang ditambahkankan. Berikut ini hanyalah beberapa dari banyak fitur yang terkandung pada Moodle 1.9.

\section{a. User Management}

Moodle secara default menyediakan tujuh tingkatan (previlege) untuk untuk mengurangi tingkat keterlibatan administrator. Lebih jelasnya, berikut merupakan tujuh tingkatan user tersebut: Administrator, Course Creator, Teacher, Non-editing teacher, Student, Guest, dan Authenticated User.

b. Course Management

Pada Moodle, yang dapat memanajemen course yang ada hanyalah user dengan role sebagai guru (teacher/non-editing teacher), dan tentu saja admin yang dapat melakukan apapun. Walaupun user dengan role course creator dapat menciptakan suatu course, namun user tersebut tidak dapat memodifikasi course yang telah ia ciptakan bila ia tidak mengajar di course tersebut (bukan sebagai teacher). Course pada Moodle memiliki beberapa format, yaitu LAMS course format, SCORM format, Social format, Topics format, Weekly format, dan Weekly format - CSS/No table. Moodle menyediakan lima jenis materi pelajaran yang bersifat statis, materi pelajaran bisa dibaca siswa, tetapi tidak bisa berinteraksi dengan halaman teks, halaman html, link dengan web melihat derectoris dan tampilan label berupa tulisan atau gambar. Sebagai tambahan agar proses belajar mengajar lebih interaktif. Moodle menyediakan berbagai aktifitas yaitu : Assignments, Choices, Lesson, Quizzes, Surveys, dan Journal. Moodle juga menyediakan lima jenis fitur untuk aktivitas interaksi antara siswa dengan siswa maupun siswa dengan guru. Fitur tersebut adalah : chat, forum, glossary, wiki, dan workshop. Jurnal pengembangan $e$ learning dengan menggunakan Moodle ini dibatasi hanya untuk mempelajari metode pengembangan dan kelayakan e-learning. 


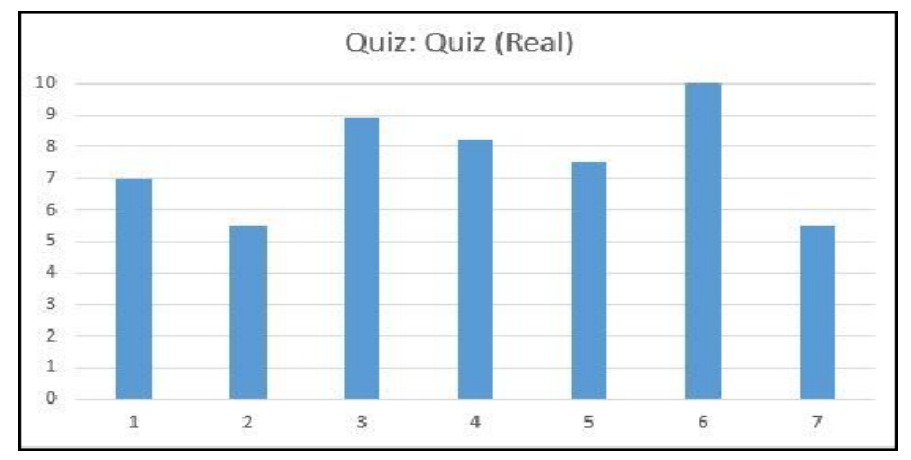

Gambar 2. Contoh Hasil nilai pengerjaan soal

Contoh hasil nilai quiz dari salah satu matakuliah yang diberikan dalam aplikasi e-learning ditampilkan dalam bentuk grafik diperlihatkan dalam Gambar 2.

\subsection{HASIL PERANCANGAN}

Kegiatan yang kami lakukan dalam penggunaan Moodle sebagai media e-learning Universitas Trisakti dikembangkan melalui tiga tahap yaitu analisis, perancangan dan pengembangan [5]. Analisis permasalahan dilakukan dengan menggunakan use case dan flow chart dan uraian lebih lengkap dari setiap kegiatan adalah sebagai berikut :

a. Pembuatan Use Case

Use Case merupakan daftar tindakan yang mendefinisikan interaksi antara peran (UML sebagai aktor) dan sebuah sistem untuk mencapai tujuan. Aktor dapat berupa manusia atau sistem eksternal lainnya. Aktor pada penelitian kali ini adalah admin dan guest yang mendapatkan izin akses. Use Case Edu Usakti dapat dilihat pada Gambar 3 dibawah ini.

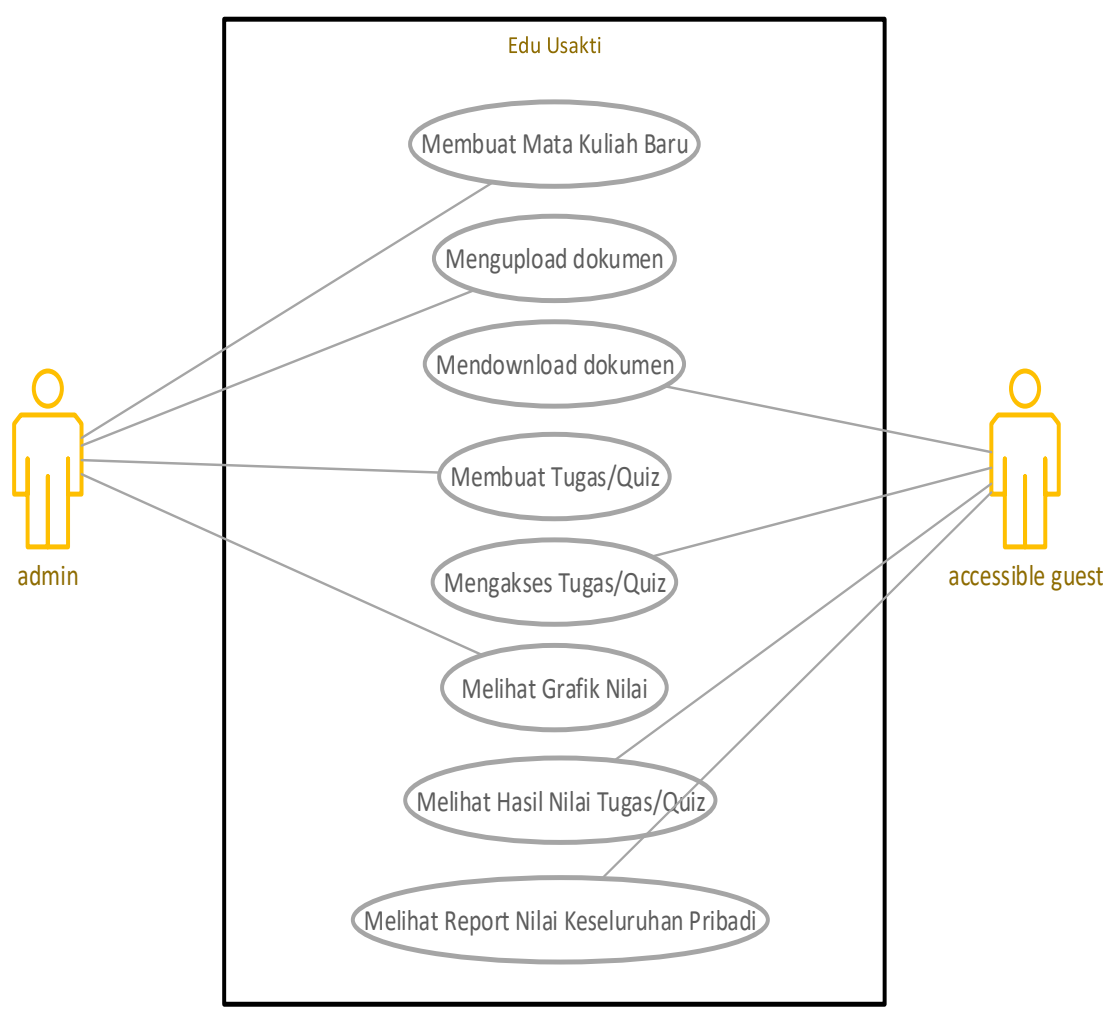

Gambar 3. Use case 
b. Pembuatan Flowchart

Flowchart merupakan diagram yang menampilkan urutan pekerjaan yang bertujuan

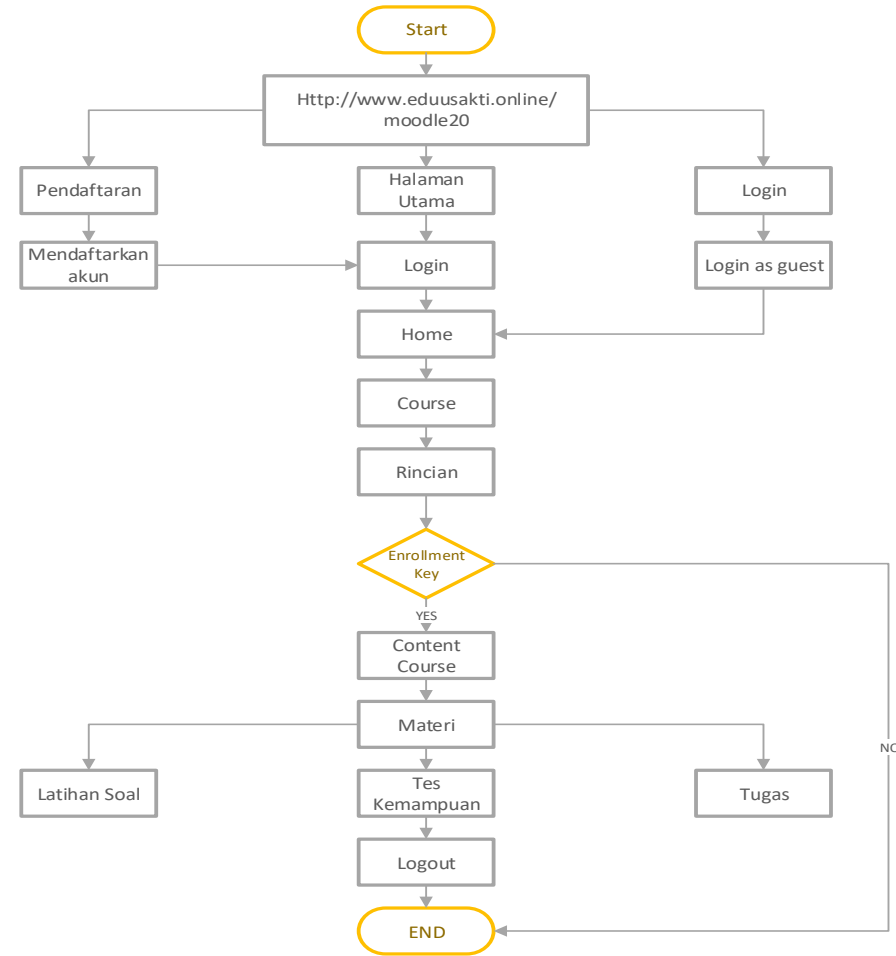

Gambar 4. Flowchart

untuk memberikan informasi kepada kita ketika berhadapan dengan suatu proyek atau proses. Flowchart Edu Usakti diperlihatkan pada Gambar 4.

c. Perancangan Tampilan Halaman Website

Tampilan rancangan untuk login dari aplikasi e-learning Edu Usakti yang dibuat,

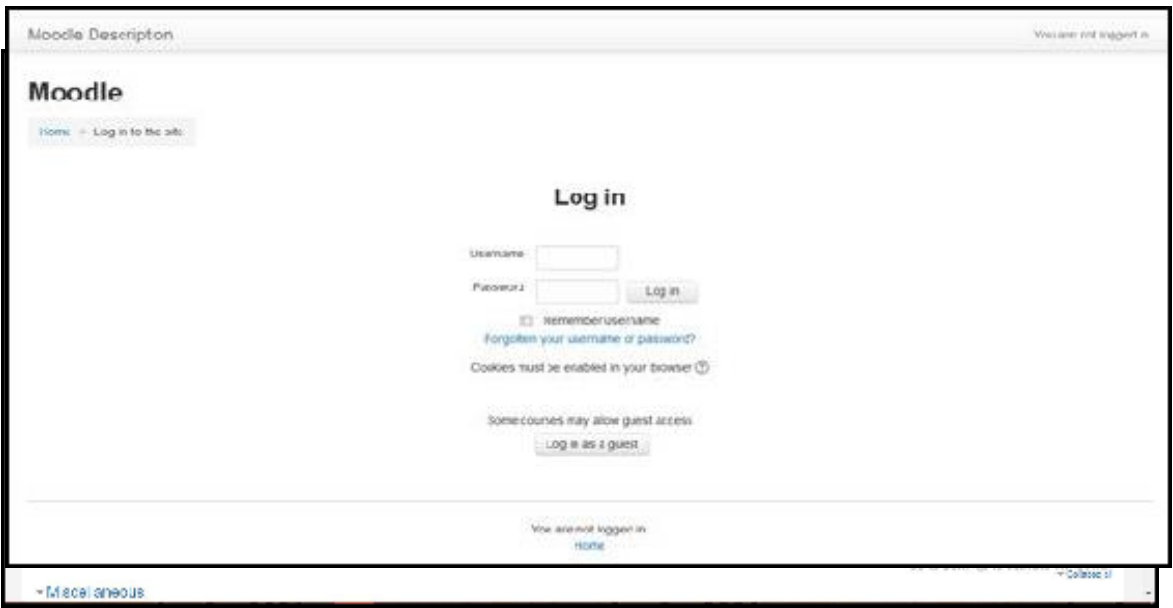

Gambar 5. Halaman Awal Edu Usakti

diperlihatkan dalam Gambar 5 


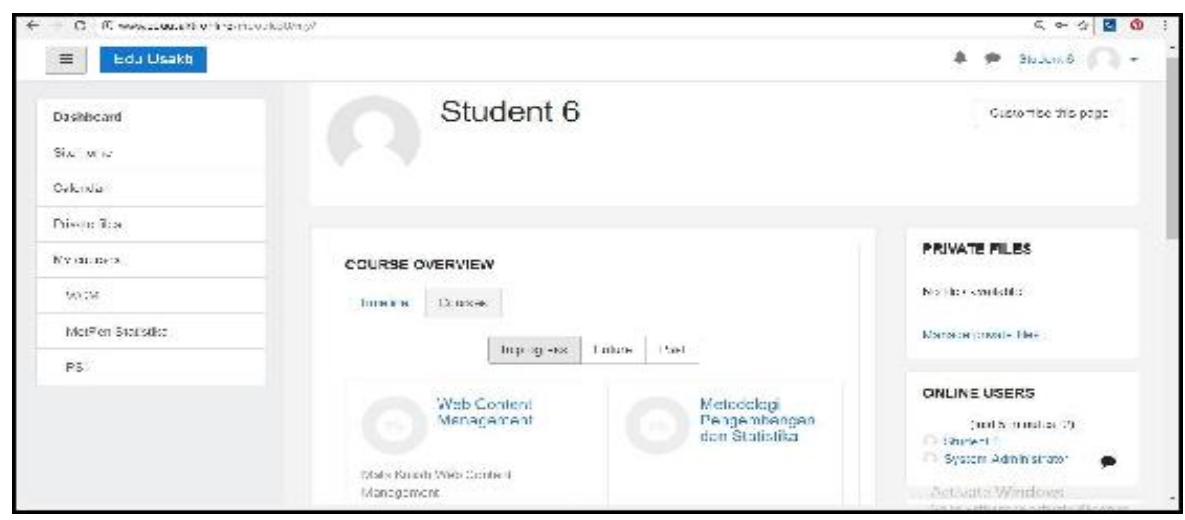

Gambar 6. Dashboard Student

Tampilan dashboard peserta e-learning diperlihatkan pada Gambar 6.

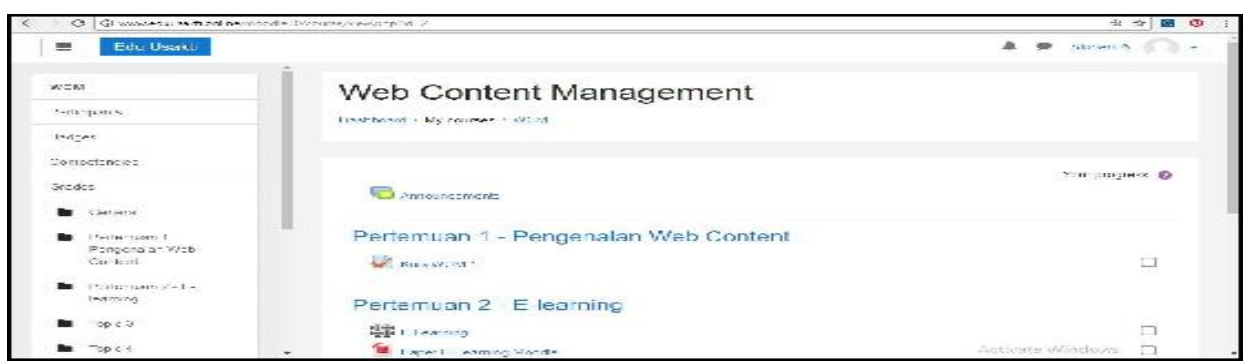

Gambar 7. Tampilan Matakuliah Web Content Management

Begitupun tampilan salah satu mata kuliah yang ada dan diajarkan dalam e-learning yaitu Web Content Management diperlihatkan pada Gambar 7.

\section{HASIL DAN PEMBAHASAN}

Untuk menentukan keefektifan situs rancangan e-learning yang telah dibuat, kami mengadakan survey yang diisi oleh siswa e-learning. Survey ini dilakukan untuk mengetahui tingkat kerelavanan antara e-learning dengan yang siswa harapkan, tingkat hubungan interaktif yang ada dan yang siswa harapkan, tingkat bantuan dari para tutor / guru, tingkat hubungan dengan teman sesama siswa dan tingkat interpretasi [3]. Survey dilakukan pada 8 mahasiswa yang belajar pada website Edu Usakti.

Metode pengumpulan data yang digunakan adalah menggunakan fitur survey yang disediakan oleh Moodle. Survey berisi pernyataan yang harus dijawab oleh mahasiswa berupa : hampir selalu, sering, kadang-kadang dan jarang.

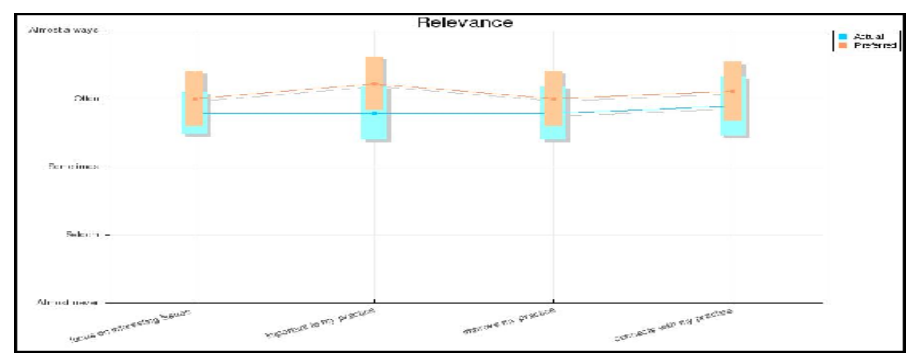

Gambar 8. Survey Relavance 
Hasil survey seperti diperlihatkan dalam gambar 8, menunjukan bahwa tingkat relevansi berada dalam rentang often (sering) atau sesuai dengan kebutuhan. Sehingga, Edu Usakti berfokus pada masalah yang menarik, dapat dianggap penting untuk latihan, dapat meningkatkan praktek dan dianggap berhubungan dengan latihan mahasiswa.

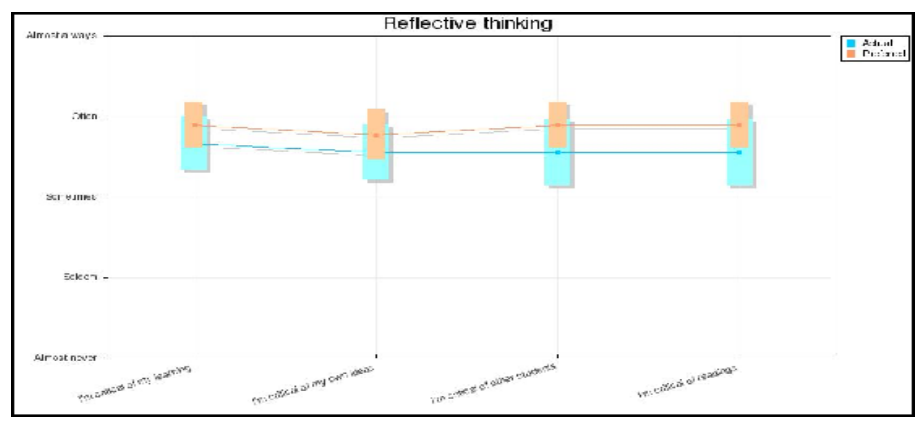

Gambar 9. Survey Reflective Thinking

Gambar 9 menunjukan hasil survey yang telah dilakukan tentang pemikiran reflektif, terlihat para siswa cenderung sering bersikap kritis, baik terhadap pembelajaran dan idenya sendiri, terhadap siswa lain maupun dan terhadap bacaan. Hasil survey juga menyatakan bahwa mereka tetap menginginkan bisa bersikap lebih kritis lagi.

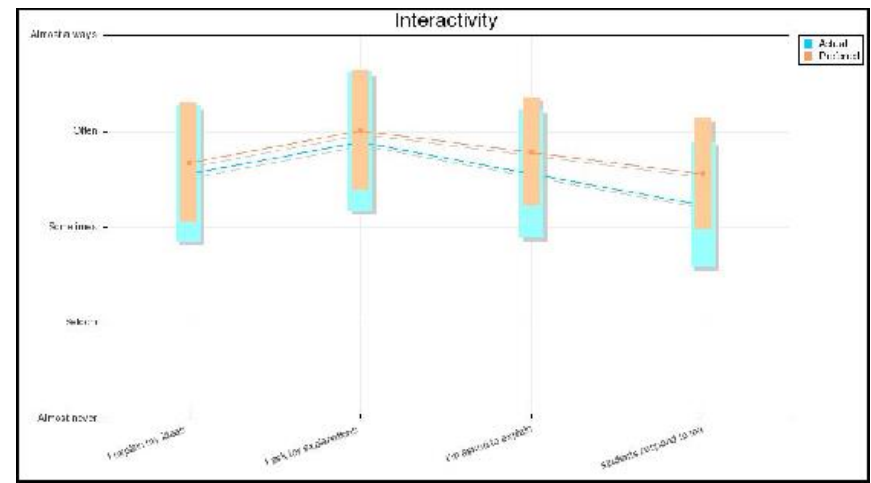

Gambar 10. Survey Interaktivitas Mahasiswa

Pada hasil survey interaktivitas seperti ditunjukan dalam Gambar 10, tampak bahwa para mahasiswa cenderung sering dalam menjelaskan pemikirannya masing-masing, meminta penjelasan ke dosen, menjelaskan materi oleh dosen dan para siswa saling merespon.

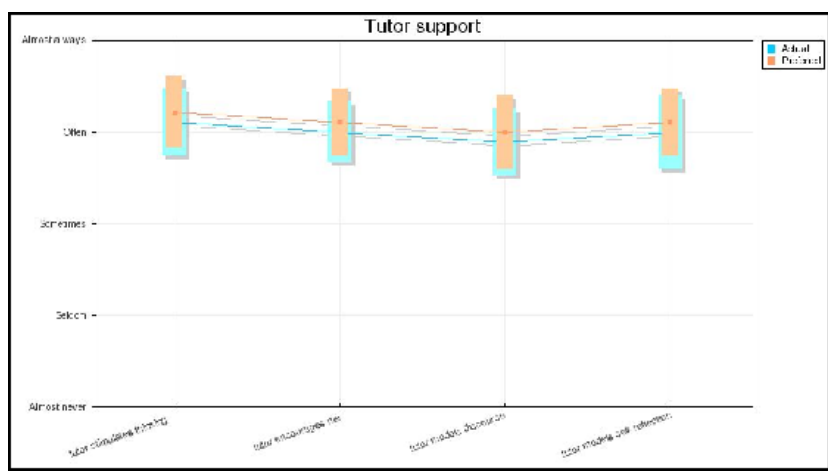

Gambar 11. Survey Dukungan Dosen 
Gambar 11 menunjukan bahwa dukungan dari pada dosen juga masuk ke dalam kategori baik, yakni dosen dianggap dapat merangsang pemikiran, memberikan dorongan, memberikan diskusi dan menjadi self-reflection.

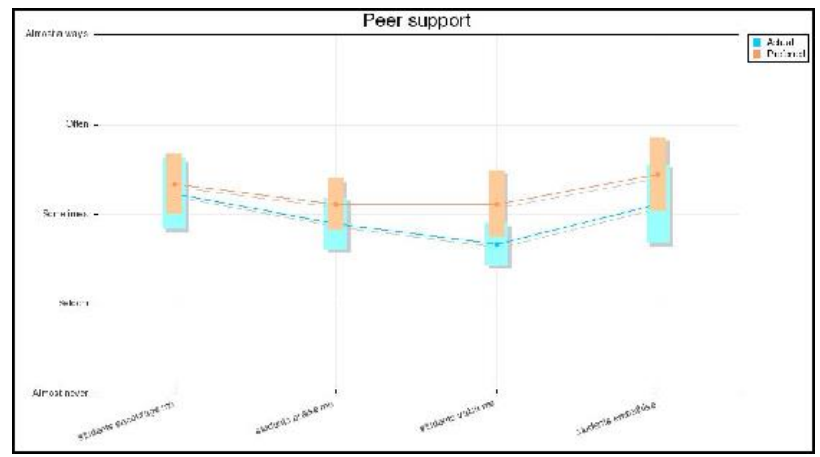

Gambar 12. Survey Dukungan Teman Sekelas

Pada survey dukungan teman sekelas seperti ditunjukan dalam gambar 12 terlihat, hasil aktual berada dalam rentang seldom (jarang) dan sometimes (kadang-kadang). Para mahasiswa saling mendukung temannya satu sama lain meski tidak sering dan kadang saling memuji dan berempati dengan temannya. Pada sikap dukungan saling menghargai berada di rentang "jarang”.

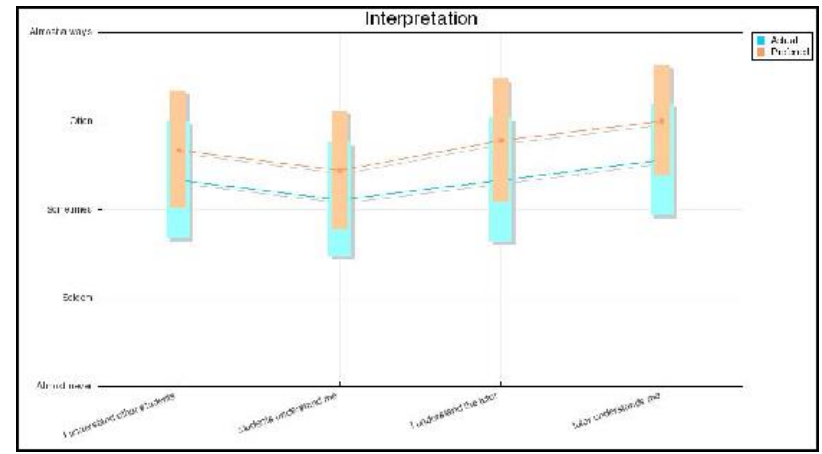

Gambar 13. Survey Interpretasi

Hasil survey yang ditunjukan dalam gambar 13, menunjukan hasil interpretasi antara mahasiswa dengan mahasiswa lain serta dosen dengan mahasiswa berada dalam rentang kadang-kadang (sometimes). Namun, mahasiswa mengharapkan interpretasi lebih tinggi untuk kedepannya.

Berdasarkan hasil survey, dapat dilihat bahwa mahasiswa dari Edu Usakti menginginkan agar website e-learning Edu Usakti lebih meningkatkan lagi performanya di segala bidang. Survey tersebut menyatakan dengan jelas bahwa hal yang mereka inginkan lebih tinggi daripada kenyataan yang ada. Itu menjadi tugas besar bagi kami pengembang e-learning Edu Usakti untuk meningkatkan performa kami. Mahasiswa mengharapkan agar kerelavanan antara e-learning dengan yang diharapkan, hubungan interaktif, bantuan dari para tutor, hubungan dengan teman sesama siswa dan tingkat interpretasi harus dapat ditingkatkan.

Proses pembelajaran di kelas pada perguruan tinggi termasuk jenis jasa yang cenderung dikategorikan sebagai kelompok jasa murni, mengingat dominasi pelayanan yang diberikan dibandingkan unsur penawaran barangnya. Oleh karena itu, karakteristik yang menonjol dari jasa pembelajaran di kelas ini adalah sifat stimulan (proses produksi dan konsumsi terjadi bersamaan) serta sifat heterogennya kualitas. Pelayanan pendidikan perguruan tinggi yang berkaitan dengan 
proses pembelajaran di kelas (online) juga termasuk jenis jasa yang berbasis orang, dimana mahasiswa dan dosen (guru) terus berinteraksi selama proses tersebut. Hal-hal inilah yang menyebabkan pentingnya peran dosen dan mahasiswa dalam proses pembelajaran di kelas.

\section{KESIMPULAN DAN SARAN}

Website ini dapat menjadi sarana belajar bagi penggunanya dan bagi siapapun yang ingin belajar mengenai Sistem Informasi terutama mahasiswa Universitas Trisakti. Dengan media pembelajaran secara online ini dapat menambah wawasan pengetahuan dan juga dapat mempermudah pengguna untuk belajar dimana saja dan kapan saja karena berbasis online. Website E-Learning ini masih harus dikembangkan atau dimodifikasi lebih lanjut. Kekurangan dari e-learning ini, masih baru mencakup matakuliah umum pada Jurusan Sistem Informasi. Besar harapan kedepannya agar dapat mencakup materi pembelajaran yang lebih luas. Disamping itu, design website E-learning masih kurang menarik jadi masih harus dipercantik lagi. Tambahan, untuk pengembang agar kedepannya dapat menambahkan plugin dan melakukan promosi sosial media agar website e-learning makin dikenal lebih luas.

\section{DAFTAR PUSTAKA}

[1] Naidu, S. (2006). E-learning: A Guidebook of Principles, procedures and Practices (2nd edition). New Delhi: CEMCA.

[2] Pratama, D. A., Atmaja, D.B., Reinhad, H., \& Santoso, G.B. (2019) Rancangan Implementasi Enterprise Resource Planning Berbasis Open Source Menggunakan Software Dolibarr Pada Perusahaan Pt Alwaysproblem. Jurnal Penelitian dan Karya Ilmiah Lembaga Penelitian Universitas Trisakti, 4(2), 2019.

[3] Rahayu, F. \& Ekasari, A. (2012). Bagaimana Mengevaluasi Proses Pembelajaran di Kelas: Sebuah Model Evaluasi Alternatif. Jakarta Model Evaluasi Alternatif. Jakarta: Universitas Trisakti.

[4] Sanctos, F. O, Tukandan, P \& Julian, S. E. (2017).Media Pembelajaran Programmable Logic Controller Berbasis Remote Laboratory Menggunakan Jaringan Internet. Jakarta: Universitas Trisakti.

[5] Tiara. (2015). Pengembangan Media E-Learning berbasis Moodle pada Kompetensi Dasar Jurnal Khusus Untuk Siswa Kelas XII IPS Semester Gasal di SMA Negeri 4 Jember. Surakarta: Universitas Sebelas Maret.

[6] Zyainuri \& Marpanaji, E. (2012). Penerapan E-Learning MOODLE Untuk Pembelajaran Siswa yang Melaksanakan Prakerin. Yogyakarta : Universitas Negeri Yogyakarta. 